\title{
Transgeracionalidade PSíQUiCa:
}

\author{
UMA REVISÃO DE LITERATURA
}

\author{
Mauro Pioli Rehbein; Daniela Scheinkman Chatelard
}

Universidade de Brasília, Asa Norte, Brasília, DF, Brasil

\section{RESUMO}

Este artigo trata do tema da transmissão psíquica geracional. Através de uma revisão narrativa da literatura psicanalítica sobre a transgeracionalidade psíquica, objetiva-se apresentar as diferentes fundamentações teóricas e categorias conceituais da transmissão que emergiram na psicanálise. A transmissão psíquica é um processo inconsciente, ocorre em nível não-verbal, no qual o sujeito está inserido e alienado numa cadeia genealógica de significantes. A metodologia utilizada para a elaboração do artigo restringiu-se aos seguintes critérios: textos psicanalíticos clássicos, como de Freude Lacan, dos húngaros Abraham e Törok, e dos psicanalistas da escola francesa Quatrième Groupe, que privilegiou o tema da transmissão psíquica geracional. A partir de artigos psicanalíticos, publicados em revistas cientificas brasileiras, objetiva-se promover reflexões e articulações com a temática. Embora os diferentes construtos, o trauma, as relações intersubjetivas e o não dito, constituam lugares-comuns nas transmissões psíquicas.

Palavras-chave: transmissão psíquica geracional; transgeracional; intergeracional; subjetividade; psicanálise.

\section{Psychic transgenerationality:}

\section{A LITERATURE REVIEW}

\begin{abstract}
This article is concerned with psychic generational transmission. By means of a narrativepsychoanalyticliterature review focused on psychictransgenerationality, the transmission's different theoretical foundations and conceptual categories which emerged from psychoanalysis are presented. Occurring in non-verbal realms, psychic transmission is an unconscious process into which the alienated subject is embedded in a genealogical signifier chain. The writing of this article is based upon a methodology restricted to the following criteria: classical psychoanalytic texts, like those by Freud, Lacan, the Hungarian Abraham and Törok and those written by the psychoanalysts from the French School of Quatrième Groupe, which privileged generational psychic transmission theme.

\footnotetext{
‡Endereço para correspondência: Universidade de Brasília, Instituto de Psicologia, Departamento de Psicologia Clínica. Campus Universitários Asa Norte Laboratório de Psicanálise dos Processos de Subjetivação. Asa Norte - 70910-900 - Brasilia, DF - Brasil.

E-mail:maurorehbein@gmail.com,dchatelard@gmail.com.
} 
Based on psychic articles published in Brazilian scientific magazines, reflections and articulations linked with the thematic are made. Despite the fact that the different constructs, the trauma, the inter-subjective relationships and what is non-said, they constitute common-places in psychic transmission.

Keywords: generational psychic transmission; transgenerational; intergenerational; subjectivity; psychoanalysis.

\section{INTRODUÇÃo}

A proposta deste artigo é realizar uma revisão da literatura psicanalítica que trata da transmissão psíquica geracional. Objetiva-se apresentar as principais correntes teóricas da transgeracionalidade psíquica que emergiram na psicanálise, bem como destacar as diferentes categorias conceituais que as delimitam e as caracterizam. Destacam-se, em Abraham e Törok (1995), o trauma como a impossibilidade de simbolização; a cripta que guarda uma situação vivida como traumática e conservada por um recalcamento conservador, numa clivagem do eu; o fantasma enquanto formação do inconsciente, resultante de uma cripta, e transmitido por um dos pais ao inconsciente do filho, e que funciona como um estranho ao lugar do sujeito. Em Freud, o narcisismo e os ideais enquanto herança dos pais, as pulsões e seus destinos, e enquanto montagens constituídas, os processos de identificação e a denegação; o complexo de Édipo e a castração, enfim, a culpa. Com os psicanalistas do Quatrième Groupe teremos a apresentação dos diferentes enfoques dados à transmissão psíquica a partir dos conceitos psicanalíticos de base, tais como laço, denegação, identificação, pulsão, trauma, transferência e outros. Já em Lacan, como veremos mais a partir das reflexões, a questão da linguagem e das cadeias significantes nas quais o sujeito está inserido e é constituído e efeito. A linguagem como condição do inconsciente e o enlace do sujeito ainda no início da vida na estrutura discursiva.

Com isso, pretende-se promover uma discussão objetiva a partir de textos publicados em revistas científicas nacionais, encontrados na base de dados do Scielo, LILACS e PePSIC, assinalando a predominância ou tendência de correntes e dos conceitos aplicados.

Para tanto, descreve-se a definição da transmissão psíquica geracional, suas características e delimitações teóricas. Faz-se menção aos principais textos de Freud, os que fundamentam essa metapsicologia, que são retomados pela escola Húngara, Ferenczi e Balint, e também disseminados por seus representantes, Abraham e Törok, na França. Estes, por sua vez, desenvolvem novos conceitos psicanalíticos na temática da transgeracionalidade psíquica na década de 1970, influenciando sobremaneira o denominado Quarto Grupo de Psicanálise. Desse grupo de psicanalistas que privilegiou o tema em questão, destacamos a delimitação teórico-clínica, tendências e conceitos aplicados. Incluem-se também, nesse grupo, textos de psicanalistas argentinos que comungam com aquele grupo francês, os quais produzem teorias e práticas clínicas da transmissão psíquica que são referência na produção aqui investigada. 
Por fim, a partir da leitura dos artigos promove-se a discussão e a reflexão quanto ao predomínio teórico-clínico utilizado em estudos de casos, constatandose uma forte aplicação da fundamentação teórica psicanalítica da metapsicologia de Freud com a articulação das teorias da transmissão psíquica geracional com a psicanálise lacaniana e com os construtos produzidos pelo Quarto Grupo.

\section{Transgeracionalidade PSíQuica}

Para apresentar a definição e delimitação da Transmissão psíquica geracional recorre-se ao texto Eclosão dos vínculos genealógicos e transmissão psíquica, de Olga B. Ruiz Correa (2001a). A transmissão psíquica geracional e seus mecanismos são articulados com os conceitos elaborados pela metapsicologia psicanalítica, tais como os de pulsão, narcisismo, identificação, trauma, recalcamento, denegação, significantes, fantasma e outros. A transmissão psíquica geracional ocorre por processos psíquicos inconscientes constituintes de subjetividades via linguagem, simbólicos, e também nas dimensões do imaginário e do real e nos vínculos geracionais familiares. A transmissão psíquica ultrapassa os campos do intrasubjetivo e do intersubjetivo, aquele restrito ao indivíduo, tomando a dimensão e o espaço do transubjetivo, expandindo a clínica a uma nova percepção da dimensão de trabalho.

A transmissão geracional tem duas modalidades - a intergeracional, transmitida pela geração mais próxima, pelos pais, na qual o material pode ser transformado e metabolizado, ou ainda comprometido e transmitido à próxima geração; e a transgeracional, em que o material psíquico da herança genealógica é inconsciente e não simbolizado, não é integrado no psíquico, este apresenta lacunas, elementos foracluídos, encriptados, e é transmitido por várias gerações.

A família é o espaço privilegiado para a transmissão transgeracional, nela se articulam diversos mecanismos de identificação. As funções de contenção e elaboração do grupo familiar, como por exemplo, nas situações de violência ficam comprometidas em duas dimensões - na intrafamiliar, com as agressões de todas as ordens, e na político-social, com as guerras, ditaduras, genocídios e miséria.

O silêncio da violência ou ruptura dos diversos vínculos geracionais são o denominador comum que percorre a falta de inscrição do sujeito na sucessão das gerações e no tecido grupal comunitário, limitando ou impedindo o acesso aos processos de simbolização que organizam uma cadeia de significantes (CORREA, 2001a, p. 65).

A necessidade de amenizar os efeitos devastadores e traumáticos desses fatores em jogo na transmissão psíquica, tais como as somatizações, as mortes, os crimes, os abortos, as violências dos acontecimentos sociais e rupturas geracionais recorre e se manifesta por defesas, tais como pela denegação, clivagem e projeção, mecanismos que acabam contribuindo com a formação dos segredos de família. Outra possibilidade é no caso das heranças psíquicas não serem assumidas e simbolizadas, ou processadas pela família, e assim transmitidas, 
dando continuidade geracional e manutenção de lacunas, de proibições, de segredos, de recalcamentos e esquecimentos na história da família, ou, ainda, provocando o surgimento de novas rupturas. Como se trata de simbólico, o que importa do segredo não é necessariamente o seu conteúdo, mas a interdição de falar. Portanto, têm-se aí duas possibilidades: a demanda/necessidade de falar e a de ficar calado. O que é transmitido de uma geração a outra, o intergeracional, é justamente essa clivagem, que vem ou se constitui na forma de um segredo.

A transmissão psíquica ocorre por mecanismos de identificação e por investimento libidinal de representações fantasmáticas que procedem de uma forma de organização do psiquismo do sujeito. Portanto, a transgeracionalidade psíquica comporta a alienação do sujeito e, por conseguinte a violência dos seus efeitos devastadores e enquanto patologia vincular intersubjetiva, por consequência dos traumas acumulados. Estes também herdados pela transmissão referem-se à perda ou à limitação dos elementos que garantiriam os referenciais sociais e metapsíquicos.

\section{Antes a metapsicologia de Freud}

Sem exceção, os textos e artigos dos autores pesquisados apresentaram suas fundamentações teóricas partindo dos textos clássicos de Freud, que delineiam os processos e mecanismos da transmissão psíquica. Os textos de Freud mais utilizados são aqui articulados de forma sintética, pontuando os conceitos e processos que dizem respeito à transmissão psíquica. Abraham e Törok, sobretudo o primeiro, fazem uma leitura de referência a Ferenczi e a Freud, com crítica a este, mas dialogando com ambos para o desenvolvimento e articulação dos conceitos metapsicológicos, e, diga-se de passagem, a crítica a Lacan, não obstante trabalharem os conceitos de cripta e fantasma permeados pela alienação da subjetividade. Dentre os teóricos que discorrem sobre o assunto da transmissão psíquica que também revisitam Freud estão Puget, Faimberg e Kaës, e outros.

Freud (1974[1914]) em Sobre o Narcisismo: uma introdução vai dizer que o indivíduo leva uma existência dupla, uma para atender as suas finalidades e a outra como um elo numa corrente, que atende contra a sua vontade ou involuntariamente. "Ele é o veículo mortal de uma substância (possivelmente) imortal - como o herdeiro de uma propriedade inalienável, que é o único dono temporário de um patrimônio que lhe sobrevive" (FREUD, 1974[1914], p. 94-95). Quanto aos pais, Freud destaca que a atitude desses para com os filhos é uma revivescência e reprodução de seu próprio narcisismo renascido, que remonta à infância, portanto infantil. Compulsivamente, os pais atribuem ao filho todas as supostas perfeições, esquecendo as deficiências ou limitações dele. Com isso, suspendem, em favor do narcisismo, em nome da criança, o funcionamento das aquisições culturais que foram obrigados a respeitar. A criança herdará os sonhos dourados e desejos irrealizados dos pais. Freud assinala que a formação, no indivíduo, de um ideal do eu, pelo qual a consciência tentará realizá-lo, surgiu da influência crítica de seus pais, que a transmitiram pela voz. A instituição da consciência foi, antes, uma personificação da crítica dos pais e, depois, da sociedade. 
Com o texto das pulsões (1974[1915]), e seus destinos, o que vai interessar diretamente quanto à transmissão, sobretudo, os seus destinos, a reversão a seu oposto, o recalcamento, o retorno em direção ao próprio eu do indivíduo e a sublimação. O processo civilizatório, a moral, a cultura são montagens pulsionais produzidas pelo homem para organizar os modos de satisfazer suas necessidades. As pulsões são montadas a partir das demandas dos pais. Para Freud (1974[1915], p. 145) "o indivíduo é um apêndice temporário e passageiro do idioplasma quase imortal, que é confiado a ele pelo processo de geração." O sujeito carrega dívidas simbólicas inscritas no seu corpo.

Em O Mal-estar na Civilização, Freud (1974[1930]) vai deixar claro que uma das fontes de sofrimento provém da inadequação das regras que tentarão regular as relações mútuas dos homens na família, no Estado e na sociedade. Todas as fontes de sofrimento, bem como as defesas contra este, fazem parte dessa mesma civilização. A civilização, a vida humana em comum, só é possível com a constituição do poder de uma comunidade, estabelecido como direito, que substitui o poder do indivíduo, conhecido como força bruta. Nesse texto, Freud volta a falar da sublimação das pulsões como aspecto evidente do desenvolvimento cultural na vida civilizada, tornando possíveis as atividades psíquicas superiores, como as científicas, artísticas e ideológicas. A renúncia ou a não satisfação de pulsões poderosas geraria a "frustração cultural", que Freud vai dizer que domina o campo das relações sociais entres os seres humanos e que seria a causa da hostilidade contra a qual as civilizações lutam. A comunidade desenvolve um superego cultural, e este é transmitido pela própria cultura.

Em Psicologia de Grupo e a análise do ego (FREUD, 1974[1921]), Freud assinala que a identificação é a mais remota expressão de laço social e desempenha papel importante na história primitiva do Complexo de Édipo. A identificação constitui a forma original de laço emocional de um objeto com o outro; de maneira regressiva, a identificação se substitui por uma vinculação objetal libidinal, por meio da introjeção do objeto no eu; e a identificação parcial que pode se dar com novas percepções de qualidades de outrem, que não é objeto sexual, proporciona o surgimento de novos laços sociais. No processo de identificação, o eu se enriquece com as propriedades do objeto introjetado. Para isso, há que se considerar o objeto perdido para que o objeto seja novamente reencontrado e criado dentro do eu.

O texto A Negativa (FREUD, 1974[1925]), traduzido por "a denegação", como mecanismo que permite a ideia ou imagem recalcada ter acesso à consciência, porém com a condição de que seja denegada, como forma de suspensão do recalcamento, ou seja, uma aceitação intelectual, mas não afetiva, portanto o recalque continua e assim é transmitido para as gerações ulteriores. $\mathrm{O}$ julgamento intelectual tem como afirmar ou denegar o conteúdo de pensamentos. O julgar é uma continuação do processo original por meio do qual o eu, levado pelo princípio do prazer, integra ou expele coisas de si. Freud aponta que o desejo geral de denegar seria um sinal de uma desfusão de pulsões efetuada pela retirada de componentes libidinais. 
Em Totem e Tabu, Freud (1974[1913]) trabalha o mito da origem da lei, com o totemismo, a morte do pai primevo, a interdição do incesto enquanto lei, remetendo às leis gerais, que regem as sociedades e seus tabus, que ainda existem, e o surgimento da cultura, da religião, da sociedade, das artes que convergem para o Complexo de Édipo, por conseguinte, ao complexo de castração. Vai falar da realidade psíquica que está por trás do sentimento de culpa dos neuróticos. No princípio, foi o ato, nas gerações seguintes, a inibição e a culpa, como heranças de disposições psíquicas. "Aquilo que herdaste de teus pais, conquista-o para fazê-lo teu" (FREUD, 1974[1913], p. 188). Freud faz a oposição entre os conteúdos de transmissão, um constituído pelos objetos simbólicos e as aquisições culturais e o outro que o narcisismo organiza.

Observa-se que Freud, em seus textos, a partir dos quais foram desenvolvidas as questões da transgeracionalidade psíquica, tratou a transmissão como transferência, Übertragung. Esta enquanto transmissão do desejo, por meio das ações das palavras dos pais sobre a criança, fundando a relação intersubjetiva de transmissão psíquica geracional.

\section{OS HÚNGAROS E O ENFOQUE NA TRANSGERACIONALIDADE PSÍQUICA}

A escola húngara, com seus representantes Sándor Ferenczi e Michael Balint, influenciou diretamente Nicolas Abraham e Maria Törok; estes, por sua vez, também contribuíram e exerceram influência em Paris, sobretudo nos fundadores da escola de psicanálise, mais conhecida como o Quarto Grupo, Quatrième Groupe. Abraham e Törok elaboraram os conceitos fundamentais na problematização, teórico-clínica, da transmissão psíquica geracional. São eles: os efeitos dos segredos de família transmitidos por gerações; a chamada clínica do fantasma ou assombração; o luto impossível, indicando uma patologia de um ente querido; lutos não elaborados, o luto indizível que instala no sujeito uma sepultura secreta; a identificação secreta com um outro (fantasma de incorporação); e a chamada cripta, que seria o sepultar intrapsíquico de uma vivência vergonhosa e impalavrável (ABRAHAM; TÖROK, 1995). Para eles, o inconsciente é transindividual, e todo sofrimento psíquico corresponde a um trauma.

Segundo Abraham e Törok, quando algum acontecimento torna-se segredo familiar, enquanto organização patológica, via recalcamento "conservador", está ligado ao luto e remete à vergonha da perda do objeto, impossibilitando a comunicação social. A cripta significa o que está oculto, velado, secreto, obscuro, ininteligível, e o "criptóforo" é portador em si de uma cripta, de um segredo, esta como um túmulo, a realidade para ele nasce com a exigência de permanecer escondida. Para o criptóforo, trata-se de um desejo realizado e que já se encontra sepultado, porém incapaz de renascer e de virar pó. A cripta corresponde a um lugar definido, situado entre o inconsciente e o ego da introjeção. Inconsciente artificial instalado no ego, o qual cumpre o papel de guardião desse túmulo. E o que se mantêm na cripta são palavras sepultadas vivas, indizíveis. As atitudes que favorecem a espessura da parede do túmulo favorecem também a eclosão da psicose (ABRAHAM; TÖROK, 1995). A cripta é um sintoma da patologia da 
transmissão psíquica, um território encravado entre a dinâmica do inconsciente e o ego da introjeção, porém instalada no núcleo do eu, um luto não efetuado de um ideal de eu não realizado, uma vergonha sepultada (ABRAHAM; TÖROK, 1995; CORREA, 2000a; ANTUNES, 2003).

Para Abraham e Törok a cripta está "constituída por uma configuração psíquica na qual um sujeito é induzido a simbolizar em relação a um outro, presente nele, na forma de um objeto psíquico interno à custa de sua vida psíquica pulsional" (CORREA, 2000b, p. 62). A questão não seria o trauma em si, mas a sua possibilidade ou limitação de elaboração. O trauma, para Abraham e Törok (1995), é definido a partir do conceito de introjeção, que, para Ferenczi, é a inclusão do objeto (de amor) no ego, no qual Abraham se referencia, portanto o trauma é uma introjeção impossível, e ocorre na dimensão intergeracional. Abraham e Törok chamam atenção para o nível de realidade, a dimensão fantasmática, e a força que outros traumas intergeracionais das fantasmáticas familiares exercem (CORREA, 2000b).

Para Abraham, o fantasma é uma formação do inconsciente, é a lacuna deixada no filho em função dos segredos de um dos pais; um dizer enterrado num dos pais, não simbolizado, ficando inconsciente para aquele, porque the causou alguma ferida narcísica. Este dizer se torna, para a criança, um morto sem sepultura. Uma lacuna retorna e é transmitida em forma de sintomas de defesa para criança.

As principais categorias conceituais desses precursores são: os mecanismos de introjeção, inclusão e incorporação, diferentes dos desenvolvidos pela psicanálise clássica. $\mathrm{O}$ mecanismo da introjeção está associado à construção de representações, às elaborações psíquicas. A patologia do traumatismo estaria, na sua origem, ligada às impossibilidades dessas ações psíquicas. No mecanismo de inclusão, as experiências são simbolizadas parcialmente pelo eu, as lacunas se devem ao caráter traumático. O mecanismo da incorporação ocorre quando a introjeção falhou. $O$ fracasso das elaborações psíquicas das experiências, portanto tomará a fantasia como a própria coisa, que será expressa no corpo, no plano motor, diante da impossibilidade de simbolização (ABRAHAM; TÖROK, 1995; ANTUNES, 2003).

\section{O Quatrième Groupe E AS VARIANTES Da TRANSMissão}

O Quarto Grupo, Quatrième Groupe, originou-se da crise institucional na Escola Francesa de Psicanálise e com as divisões no movimento lacaniano (AGUIAR, 2000, p. 236), tendo como figuras de expressão os psicanalistas JeanPaul Valabrega, Piera Aulagnier e Nathalie Zaltzman (CORREA, 2000a), dentre outros notáveis como Mijolla, Enriquez. Esse grupo tem sido referência expressiva nas produções teórico-clínicas acerca da transmissão psíquica geracional. Incluise neste tópico psicanalistas argentinos pela proximidade ao Grupo e influência que exercem na literatura selecionada. 
Este subtítulo tem por objetivo demonstrar os diferentes enfoques dados pelos autores contemporâneos à transmissão psíquica geracional e promover um diálogo com os autores de textos nacionais sobre o tema. A produção científica brasileira encontrada e referenciada foi exclusivamente para a demonstração de casos clínicos de transgeracionalidade psíquica, no entanto, utilizamos a fundamentação teórico-clínica e sua articulação.

Correa (2000b) aponta três grupos de sintomas de sofrimento psíquico, que caracterizam a psicopatologia atual, com as suas teorias e práxis, da transmissão psíquica. O primeiro deles refere-se aos defeitos ou falhas na estruturação dos sustentos ou apoios da vida pulsional. O sujeito desenvolveria formações psíquicas clivadas, não favorecendo os processos de constituição dos objetos internos estáveis, confiáveis. O segundo grupo de autores compartilha que as psicopatologias na transmissão psíquica geracional estão vinculadasà formação das identificações e contratos intersubjetivos como garantia para o desenvolvimento da subjetividade. Nesse grupo, encontra-se Aulagnier, que sustenta o conceito de contrato narcisista, que visaria à continuidade do investimento libidinal de autoconservação para o sujeito ou à comunidade da qual faz parte. René Kaës (2001), que retoma Freud, descreve um pacto denegativo que solicitaria o trabalho do inconsciente como necessário à formação do vínculo intersubjetivo em relação ao recalque e ou a denegação nos sujeitos. Para o terceiro grupo, as fundamentações das psicopatologias caracterizam-se pelos processos das representações, a construção de sentido, o processo de simbolização seria atingido e estaria relacionado aos traumatismos acumulativos e aos lutos patológicos.

\section{O TRAUMATISMO ACUMULATIVO}

Correa (2000b) apresenta a noção de traumatismo acumulativo como uma hipótese significativa das patologias transgeracionais desenvolvidas a partir dos vínculos intra, inter e transubjetivos nas situações de violência, em contrapartida ao termo trauma, utilizado por Freud. Para a autora, o traumatismo é entendido como uma vivência acumulativa não metabolizada. Isso implica considerar os mecanismos defensivos que o evitam, deixando-os no impensável, no não dito, em razão de transgredirem as regras de funcionamento e culturais da comunidade ou do grupo. "Todos nós somos portadores de uma herança genealógica que constitui o fundamento de nossa vida psíquica e que se processa no inconsciente" (CORREA, 2000b, p. 62).

\section{O PACTO DENEgATIVO}

René Kaës (2001) trabalha a transmissão psíquica geracional, sobretudo a noção de resistência intergeracional ao luto, que se apresenta em forma de dificuldades durante uma psicanálise. Seria uma situação de repetição não transformada que enquista na psique do sujeito/indivíduo. $\mathrm{O}$ autor supõe um pacto de desconhecimento ou de resistência que se estabelece entre as gerações, impedindo-as de realizarem o luto. 
A partir de pesquisas que realiza acerca dos laços intersubjetivos nos grupos de terapia e formação, Kaës (2001) constrói um modelo geral desse pacto de resistência, no qual propõe o conceito de pacto denegativo,

[...] que é aquilo que se impõe a todo laço intersubjetivo para ser oferecido, em cada sujeito, do laço com os destinos do recalcamento ou da denegação, da recusa, da rejeição ou do enquistamento no espaço interno de um sujeito ou de vários sujeitos. (KAËS, 2001, p. 45-46).

Os objetivos impostos por esse acordo inconsciente a custos psíquicos são: organizar o laço e sua complementaridade de interesse; manutenção da continuidade dos investimentos e dos benefícios ligados aos Ideais, do contrato ou do pacto narcísico (KAËS, 2001, p. 46). O que estará em jogo no laço, para Kaës, é justamente o que liga os sujeitos em seu interesse recíproco e a economia cruzada que dirige as relações na cadeia de que fazem parte. O pacto denegativo aparece comportando duas polaridades - a organização do laço e do conjunto intersubjetivo e a defensiva. Essa dupla organização dos conjuntos ocorre de forma positiva - quando sobre investimentos mútuos, comunidade de ideais e crenças, contrato narcísico e formas toleráveis de realizações de desejos -, e de negativa - quando sobre comunidade de renúncias e sacrifícios, apagamentos, rejeições e recalcamentos, "deixar de lado" e restos. Portanto o pacto denegativo tem por característica,

[...] criar nos conjuntos do não-significável, do nãotransformável, zonas de silêncio, bolsões de intoxicação, espaços-lixeiras ou linhas de fuga que mantêm o sujeito estrangeiro à sua própria história. Nos casais, nas famílias, nos grupos e nas instituições, as alianças, contratos e pactos inconscientes sustentam, principalmente, o destino do recalcamento e da repetição. (KAËS, 2001, p. 46).

Kaës se utiliza dos conceitos de imago, relação imaginária, o duplo narcísico - rivalidade e agressividade, esquemas imaginários que o sujeito constitui e instrumenta suas relações intersubjetivas. Por exemplo, na dimensão intergeracional, "o destino da morte de uma irmã ou de um irmão está intrincado no trabalho do luto dos pais por seu filho" (KAËS, 2001, p. 54), deve-se considerar as distâncias (de grau de parentesco) entre as gerações e como o sujeito interpreta a transmissão e se posiciona nisso em termos de desejo e subjetividade. A organização psíquica do sujeito, as defesas adquiridas no momento do drama, determinará os efeitos dos fatos e dos dramas vividos.

\section{A telescopagem das gerações}

O termo telescopagem das gerações é cunhado pela psicanalista Haydée Faimberg (2001a). A autora deixa clara a influência que recebeu em sua fundamentação teórica: de Freud, os conceitos de identificação; de Abraham e Törok, a noção de fantasma; de W. Braranger, a noção de morto-vivo; de A. 
Mijolla, a proposta do conceito de fantasia de identificação inconsciente; e de Aulganier e M. Enriquez, as questões da psicose; e outros, como Winnicott e G. Rosolato. O conceito de telescopagem das gerações, segundo a autora, é delimitado em sua pertinência psicanalítica e de sua clínica. A telescopagem das gerações é um tipo especial de identificação inconsciente alienante, com histórias comuns condensando três gerações, e se revela na transferência por meio da resistência narcísica. Tais identificações têm por característica serem inaudíveis e se manterem assim por muito tempo ao longo do tratamento psicanalítico. $\mathrm{O}$ adjetivo alienante, por influência de Piera Aulagnier, deve-se em função de serem as identificações constituídas também de histórias que pertencem a um outro. Para Faimberg, o conceito-chave identificação inconsciente alienante serve para o paciente resistir narcisicamente aos impasses do complexo de Édipo e ao reconhecimento da diferença de gerações.

A contratransferência/transferência têm papel central na dinâmica desse trabalho. A transferência é condição necessária para a revelação das identificações inconscientes na telescopagem das gerações. Tal revelação darse-á inesperadamente no modo como o paciente enunciará uma informação conhecida para resolver um conflito na transferência. Isso é o que determina esse conceito enquanto psicanalítico. A contratransferência é a parte sensível ao analista, que deve conter a sua angústia de não saber, não interpretando a genealogia das identificações a partir de sua teoria. Portanto, considerando a existência das identificações inconscientes, estas são reveladas ou se manifestam na transferência pelo discurso do paciente, pois este fala e escuta a partir de identificações inconscientes. O não dito é dedutível do discurso do paciente. Por isso, o respeito e pertinência do método psicanalítico para a autora.

Cabe destacar que Faimberg (2001b) considera a função da apropriaçãointrusão atributo da regulação narcísica de objeto, e que, na transmissão alienante, os pais perdem a função de fiadores do valor da investigação das verdades psíquicas para a criança, e ocupam esse lugar. Portanto a criança estará sujeita ao que é dito ou não dito pelos pais. Isso vai ao encontro do que a autora resgata de Aulagnier, o poder desmesurado da mãe (FAIMBERG, 2001b, p. 136). A autora propõe como hipótese a telescopagem das gerações como um fenômeno universal, que estaria presente em toda análise, desde que respeitadas as condições clínicas de sua descoberta (FAIMBERG, 2001b, p. 135).

\section{Os ESPAÇOS PSÍQUICOS}

A conceitualização dos espaços psíquicos, inter, intra e transubjetivo foi denominada pela psicanalista argentina Janine Puget, assinalando a capacidade de representação do aparelho psíquico frente aos diferentes vínculos e sua incidência na realidade externa (CORREA, 2000b, p. 64). Puget demarca o além das fantasias inconscientes e vida pulsional (intrapsíquico), mas a realidade construída como efeito da inter-relação de sujeitos (transubjetivo), impondo a sua estranheza recíproca e alternância entre eles, por conseguinte o imprevisível em cada encontro e a indeterminação pelo acaso e pelos fatos. O 
espaço intersubjetivo é o da estrutura familiar inconsciente, na qual a angústia subjacente é a fusão narcisista que impede a inscrição na genealogia familiar. O espaço intrasubjetivo, é "o mundo fantasmático e o imaginário de cada sujeito, constituído pelas representações do eu corporal e dos vínculos inter e transubjetivos na ausência de percepções externas" (CORREA, 2000b, p. 64). O espaço transubjetivo, é o das "representações do mundo externo real (social e físico) que o eu adquire desde o originário assim como pela mediação do superego e objetos parentais" (CORREA, 2000b, p. 64).

Nos três níveis de subjetividade, a familiar, a social e a vincular, seja ela familiar ou social, a estranheza e a alteridade serão diferentes e com conflitos específicos.Asubjetividadevincularremeteàdimensãointersubjetiva,extrapolando a dimensão intrasubjetiva. A intersubjetividade ou o espaço intersubjetivo entre os sujeitos nos vínculos está exposto à alteração e perturbação constantes em função das presenças mútuas, portanto ele é virtual e potencializado. O vínculo é definido como os componentes inassimiláveis ao próprio eu e os irrepresentáveis do outro, chamados de "estranheza" e "alteridade". Estes sustentam a distância necessária para que haja vincularidade, também estariam referenciados a valores, permutáveis, que designariam um lugar no grupo (PUGET, 2000, p. 74).

A constituição de uma subjetividade social dá sentido aos grupos ou famílias, o que resultaria, para a autora, em uma nova condição teórica à subjetividade vincular. Compreender o psiquismo por uma vertente intersubjetiva, "espaço virtual dotado de uma potencialidade que surge do efeito de alteração em virtude do efeito das presenças mútuas" (PUGET, 2000, p. 74), em contrapartida à intrasubjetiva. A chamada psicanálise vincular introduz novas categorias conceituais, tais como: "o reconhecer o estar (pertencer a) uma estrutura vincular como diferente do ser (identificações múltiplas), do qual depende o sentimento de pertença a um contexto, a um espaço" (PUGET, 2000, p. 74-75). Portanto há um deslocamento do conceito de identidade de si mesmo, em razão da subjetividade se construir a cada momento e a cada conjunto, pois o vínculo é construído a partir do efeito de trabalho resultante de imposição de presenças das diferenças entre dois ou mais sujeitos. Os intercâmbios que produzem ao sujeito, a autora os denomina de função desvinculante. Já a função vinculante depende da possibilidade de trabalho psíquico das diferenças, a presença do outro dá a qualidade subjetivante no jogo. A autora divide essas diferenças em três categorias: a diferença que possa ser processada como complementaridade ou semelhança; a que remete à alteridade, da existência do outro, portanto de outros valores; e a radical, que é da ordem da estranheza, por exemplo, valores subjetivantes incompatíveis presentes no vínculo, esses têm os seus campos de conflitos. Isso levou a autora a "instaurar a heterogeneidade, a ruptura, a desarmonia como conceitos fundamentais para o trabalho vincular e separá-lo do trabalho sobre aquilo faltante que se poderia recuperar simbolicamente" (PUGET, 2000, p. 76). 
A transmissão de eventos traumáticos, ao afetar os grupos, interrompe os intercâmbios, desorganizando os sujeitos ou estagnando a subjetividade destes significados que dizem do trauma. $\mathrm{O}$ evento se inscreve como memória traumática. A autora descreve três tipos de memória: a traumática, a ativa e memória forçada (PUGET, 2000).

\section{A Clínica do laço}

O psicanalista francês Pierre Benghozi (2000) enfoca crises e catástrofes humanitárias e seus efeitos traumáticos sobre a criança, fala da prevenção da ressonância psíquica sobre as gerações seguintes, da repetição inter e transgeracional, com o tratamento precoce das crianças, com o "remalhar", para reestruturação do sujeito, reconstrução dos continentes genealógicos familiares e do grupo comunitário. Benghozi propõe a clínica do laço, fundada em novos conceitos e de uma nova gestão "psíquica da transmissão genealógica do impensável, do indizível, do inominável e do inconfessável" (BENGHOZI, 2000, p. 90), dos processos de desligamento psíquico, assinalando a prática relativa também à dimensão intersubjetiva e grupal, utilizando-se de uma abordagem metaconceitual, interdisciplinar, psicanalítica grupal, sistêmica e psicoantropológica, para a qual tem pesquisado, e a denomina "Psicoantropologia da Vergonha". Para o autor, a vergonha seria a organizadora da transmissão transgeracional do "negativo", do não revelado, porém presente. Esta teria uma lógica que implicaria "no ataque à dignidade, ao humano" (BENGHOZI, 2000, p. 90), e, por isso, exigiria a articulação do psicoterápico e do social com o jurídico, na dimensão coletiva trabalhada pelo autor.

O autor apresenta a expressão "traumatismo como herança", e traz como ilustração a Shoah, holocausto, na qual a conspiração do silêncio e a humilhação seriam centrais nessa ressonância psíquica para os sobreviventes ou os que sofreram o trauma e na transmissão para a geração seguinte, a qual se manifestará, de alguma forma, seja nos pesadelos, seja nas histórias não contadas pelos pais. São vestígios das marcas "traumáticas presente nas modalidades da transmissão intergeracional do murmúrio do silêncio, na forma como ela engaja os fundamentos narcísicos da psique da criança e as falhas na construção identitária" (BENGHOZI, 2000, p. 92).

Para Benghozi (2000), a temporalidade psíquica não é linear, ela seria transversal, circular e diagonal. Segundo o autor, a transmissão intergeracional ocorre de uma geração para outra, há uma elaboração pela geração que herda, esta realiza uma transformação e transmite para uma terceira geração. Na transmissão transgeracional não ocorre a metabolização psíquica, portanto o não dito, o impalavrável, o inconfessável, o indizível, o inominável são transmitidos sem serem elaborados e simbolizados, mas reproduzindo os processos de repetição para as gerações subsequentes, há o temor da possibilidade da repetição da cena da violência (BENGHOZI, 2000, p. 97). 
O autor propõe possibilidades de prevenção do traumatismo psíquico de uma geração para outra sob os modos inter ou transgeracional. A prevenção da saúde psíquica das crianças ainda não nascidas via trabalho de elaboração às vítimas de experiências traumáticas; a restauração mínima dos espaços de dignidade humana, dos nomes, dos lugares, dos corpos; elaboração dos lutos, dos acontecimentos e o resgate do simbólico e da identidade; a prevenção do estresse pós-traumático; e, por fim, a necessidade de associar todas as ações psicoterapêuticas ou sociocomunitárias à intervenção jurídica, pois o judiciário é uma instituição civilizadora e promove o reconhecimento e a justiça. A observação clínica mostra a interferência dos lutos não elaborados, de situações de violência e de traumatismos, nos níveis intra, inter e transubjetivo, podem incapacitar a organização de representações e simbolizações do aparelho psíquico individual ou do núcleo familiar.

Benghozi (2000) desenvolve seus trabalhos da transgeracionalidade psíquica, voltados às questões coletivas, traumas sofridos por comunidades gerados por violências políticas, sociais, culturais, epidemias, guerras e estupros, bem como os efeitos traumáticos sobre as famílias, bebês e crianças. Nesses contextos, tratou da morte identitária de grupos, da vergonha, do continente genealógico, comunitário e familiar.

\section{O ENVELOPE GENEALÓGico}

Para a psicanalista francesa Evelyn Granjon (2000), a pré-história do sujeito corresponde não necessariamente ao passado, a ideia de um presente composto está mais próximo da atemporalidade do inconsciente. A família, por meio das gerações e alianças, é o lugar e o aparelho da transmissão psíquica, da herança recebida e formadora dos seus componentes, cada qual com um lugar na cadeia das gerações. A realidade psíquica deste grupo e dos sujeitos que a compõem, com as formações e processos do inconsciente que a mobilizam neste espaço, constituem as suas características, sua identidade e o perpetuar-se. A articulação dos diferentes espaços psíquicos remete à formação de um aparelho psíquico familiar e ou grupal, complexo e composto, denominado de envelope, que organiza espaço e tempo próprios, além de constituir funções. O encontro de um casal, da genealogia de cada um com as falhas, buracos, malogros da filiação, fazendo fracassar os processos que os metabolizariam resultam no chamado “envelope genealógico familiar" (GRANJON, 2000, p. 20).

A disfunção do aparelho psíquico se manifesta nos espaços: intersubjetivo (distúrbio da relação e comunicação), intrapsíquico e transpsíquico (parte comum e indiferenciada do grupo), e, sobretudo, nos momentos críticos da história da família, os nascimentos, mortes, partidas, as mudanças impostas pelo interior ou exterior e dos acontecimentos traumáticos (GRANJON, 2000, p. 21). A autora faz a distinção entre herança e transmissão psíquica, esta entre as gerações remete ao mito do progresso, mito que sustenta uma sociedade pela continuidade, via tradições e cultura, e pela evolução progressiva para os indivíduos e para o coletivo (GRANJON, 2000, p. 24). 
A autora destaca o papel das mães, que passam aos bebês mensagens, via processo de educação, pelos cuidados maternos, pelas palavras, pela voz, pelo modo como se ocupa do bebê, enfim, de todas as formas, e a criança capta esses sinais, essa linguagem, esses significantes que se apresentam. Essa manifestação personalizada será carregada de sentido, mas parte ficará incompreensível. A mãe é a personagem principal nessa transmissão, mas a concepção do conteúdo transmitido é familiar (GRANJON, 2000). Na noção de "contrato psicótico", que poderia resultar em autismo e psicoses da criança, a autora se inspira no "contrato narcísico" de Piera Aulagnier, a criança torna-se o negativo de seu conteúdo, pois o segredo familiar, a amnésia e os não ditos correspondem ao enigma de seu nascimento. Seria pelas identificações primárias e, posteriormente, edípicas que as mensagens negativas da transmissão transgeracional vão se fazendo presentes na organização psíquica da criança nos processos de identificação (GRANJON, 2000).

\section{REFLEXões A PARTIR DE ARTIGOS PUBLICADOS EM REVISTAS BRASILEIRAS}

Os artigos descritos a seguir foram publicados em revistas científicas nacionais, selecionados na base de dados do Scielo, LILACS e PePSIC, a maioria é de autores nacionais e alguns de estrangeiros. Busca-se apresentar as linhas de pensamento e as referências teórico-clínica adotadas pelos autores.

O artigo de Almeida (2008), "A força do legado transgeracional numa família”, fundamentado nos clássicos, sobretudo, Kaës, Herrmann e Eiguer, demonstra a clínica dos processos transgeracionais com as representações, estas podendo ser investidas por afetos, amor e ódio. A associação e a concorrência entre esses diferentes gradientes de afeto atuariam sobre o desejo. Uma luta em relação a satisfazer ou não o desejo do outro. Ser ou não ser (?). Essas representações investidas de afetos estão submetidas aos processos psíquicos de defesa e catexias e outros. O sistema de representações e os afetos, herdados pelo sujeito dos objetos parentais e ancestrais, manifestos em seus discursos e nas repetições das relações emocionais da família, são passíveis de serem alterados pelo trauma, portanto as representações conscientes e inconscientes tomam parte no movimento psíquico de inibição ou atualização do desejo. Os traumas transgeracionais, segundo Eiguer (1997 apud ALMEIDA, 2008, p. 223) remeteriam às seguintes situações: o não dito, que remete aos segredos, à cripta, aos fantasmas e à clivagem; o mal dito, à maldição praguejada por um antepassado, à palavra extraviada, mal dita, que não encontra seu estatuto de palavra; e no excessivamente dito, na genealogia, o ancestral muito presente, não deixando o recalcamento desempenhar sua função, atrapalhando a organização psíquica do sujeito e, por conseguinte, as ações deste na vida. A autora considera as heranças da família e da cultura e seus cruzamentos nas transmissões atávicas, orientando o modo de ser e estar no mundo. O sujeito da herança estaria dividido entre, por um lado, ser um fim em si e, por outro, ser o elo da cadeia intersubjetiva na qual está sujeitado. "O sujeito é nomeado, representado e situado segundo o desejo dos porta-vozes do desejo, interditos e ideais do grupo.” (ALMEIDA, 2008, p. 216). 
Almeida (2008) aponta a violência sobre o sujeito da cadeia de transmissão de determinados conteúdos, destrutivos e mortíferos, advindos de gerações passadas comprometendo-o no seu desejo, autonomia, capacidades e humor. O seu aprisionamento no páthos de antepassados demarca essa patologia e a sua tendência a perpetuar. A autora demonstra claramente trabalhar a transgeracionalidade a partir do grupo francês, associando com a psicanálise lacaniana, quando aponta para o desejo e a cadeia significante.

Angela Piva (2009), em "A Fragilidade do Símbolo e a Transmissão Transgeracional", e Carreteiro e Freire (2003), em "De mãe para filha: a transmissão familiar em questão", trazem o modo multidimensional de pensar o sujeito na psicanálise, dos vínculos na tópica intersubjetiva, o sujeito como elo numa cadeia genealógica, integrado, no paradigma da complexidade. A interdependência dos fenômenos aponta para o sujeito social, da história e do vínculo, além do sujeito do inconsciente e diferente do sujeito pulsional e das relações de objeto, sujeito gerado pela ausência do objeto, mas do sujeito que emerge da presença pela intersubjetividade.

Para Piva (2009), o destaque não está no sujeito propriamente dito, mas no vínculo. Em termos de complexidade, fala-se de rede de relações. A subjetividade é entendida como um processo de construção contínua na relação com o outro. A constituição subjetiva não se restringe às origens primitivas do sujeito, pode se constituir em uma nova origem nos vínculos. A autora ressalta a dinâmica da subjetividade como efeito dos vínculos postulados pelos precursores.

Podemos dizer que se transmitem afetos, representações, fantasias, sistemas de relação de objeto, sistemas de ideais e valores, sistemas identificatórios, mecanismos de defesa, culpas, dívidas, mitos e também, o vazio, o significante em bruto, o negativo. Nada escapa à transmissão. (PIVA, 2009, p. 78).

As falhas de representações em uma geração se repetem na outra em forma de presentes ausentes. Piva, resgatando Abraham, salienta a fragilidade do símbolo, "o que era indizível para os pais, torna-se inominável para os filhos" (PIVA, 2009, p. 82).

Carreteiro e Freire (2003) assinalam que as transmissões familiares interferem nas duas dimensões articuladas de herança do sujeito, uma enquanto social, com as incidências sociopsíquicas, e a outra, enquanto membro de uma família. Cada sujeito se apropriará dela e de formas diferentes.

O que nos chama atenção do artigo de Correa (2003), “Transmissão psíquica entre as gerações", é que ela resgata o conceito de Übertragung, de Freud, que é o conceito de transferência, no qual estaria a definição de transmissão. A tradução desse conteúdo, transmitido ou transferido, é o ponto central do trabalho psíquico da subjetividade, portanto a sua retradução e a sua transformação de uma geração para outra. Na clínica psicanalítica a transmissão está diretamente ligada à transferência e à repetição. 
Outro ponto importante da transmissão psíquica geracional comentado por Correa é quanto ao vínculo mãe-bebê. Para esta, a família constitui o berço psíquico do sujeito com seus arquivos. A transmissão é sustentada por mecanismos de identificação, com o interjogo de projeções/introjeções e incorporações, além do superego dos pais. Desse modo, o reconhecimento da alienação da subjetividade e suas falhas na transmissão psíquica dão uma nova dimensão clínica das patologias da modernidade.

Gomes e Zanetti (2009), em "Transmissão psíquica transgeracional e construção de subjetividade: relato de um psicoterapia psicanalítica vincular", também enfatizaram a clínica vincular à relação mãe-filha, e a construção das subjetividades e dos vínculos familiares, dialogando com o Kaës, Eiguer, Berenstein e Puget, a corrente argentina da psicanálise vincular, Trachtenberg, Kopittke, Pereira, Chem e Mello. A discussão de caso clínico permite relacionar a transmissão psíquica transgeracional e o estabelecimento da maternagem, além do processo psicoterápico.

O artigo de Maria Lúcia Araújo (2001), "O discurso dos pais na clínica psicanalítica com crianças: significantes transgeracionais em questão", é fundamentado na leitura psicanalítica da clínica lacaniana, na qual o sujeito é dependente do discurso familiar. Segundo Lacan (1988), o sintoma da criança é capaz de responder o que há de sintomático na estrutura familiar, e, a partir da teoria dos discursos, afirma que, quando tomamos a palavra, ocupamos um lugar, pais e filhos estão enlaçados numa estrutura discursiva. O ser humano enquanto bebê precisa da palavra do outro para sobreviver e se humanizar, e isso só ocorre com os cuidados maternos ou por quem cumpre essa função. Nessa linha, a autora complementa, a criança só poderá apropriar-se dos significantes fundamentais filiação, nomeação e sexuação - a partir do lugar que lhe é dado e reconhecido pelos pais na cadeia transgeracional. Por meio da escuta, pode-se perceber que lugar lhe foi reservado. Afirma também, referenciando-se em Debiex Rosa, que

[...] quando não é transmitido aquilo que deu origem na genealogia, isto é a história, a criança vai repetir o gozo dos pais e não os ideais do eu, pois a função do pai é remeter a criança para um saber próprio. $\mathrm{O}$ resgate da linhagem é que vai poder fazer a criança se deparar com a diferença e não com a repetição (ROSA, 2000 apud ARAÚJO, 2001, p. 2).

Os significantes transgeracionais dizem da transmissão simbólica, da linguagem, inserindo marcas no sujeito do inconsciente, posicionando-o num discurso a partir de um lugar em relação a um outro. As marcas poderão ser traumáticas ou não, inscrevendo-se no psiquismo, serão transmitidas de uma geração a outra, repetindo-se.

Araújo salienta que os significantes transgeracionais são inscrições que estão no campo do real, portanto sem significação, gerando, por conseguinte, malestar onde algo não passou para o simbólico, não foi ou não pode ser verbalizado. 
Para Lacan (1992 apud ARAÚJO, 2002), a família estabelece entre as gerações uma continuidade psíquica cuja causalidade é de ordem mental. Assim, o sintoma da criança está relacionado ao vínculo pai e mãe.

O artigo "Avosidade: a família e a transmissão psíquica entre gerações”, de Goldfarb e Lopes (2006) falam de uma abordagem historizadora quanto à transmissão psíquica entre gerações. Também trabalham os vínculos no modelo da relação mãe-bebê, e as identificações primárias, e vão ao encontro das proposições lacanianas descritas por Araújo (2001), ou seja, precisamos do Outro ${ }^{1}$ para nos constituirmos como sujeitos psíquicos. O Outro é quem transmite o legado geracional e a partir dele o sujeito escreve sua história. A transmissão depende de um trabalho psíquico que implica as identificações. O projeto identificatório, resgatado de Aulagnier (1979 apud GOLDFARB; LOPES, 2006), trata de um saber sobre os enunciados, a resposta que o sujeito tem quando se pergunta "quem sou eu?".

As autoras destacam o papel privilegiado da mãe em relação à criança, pois aquela atuará como representante do meio social externo, este via mãe, família, transmitirá os segredos, suas leis e exigências. A estrutura familiar preexiste o bebê, e este é inserido numa estrutura de funcionamento que regula as relações de diferenças e complementaridade entre os seus componentes. $\mathrm{O}$ fracasso das transmissões subjetivantes estaria no déficit da autoridade paterna, gerando confusão de papéis e de valores e insustentabilidade dos laços. "Mais do que alguma coisa a dar e receber, há entre as gerações algo a ser transmitido: a função paterna e materna." (GOLDFARB; LOPES, 2006, p. 9).

Nessa mesma linha, a autora Marie Rose Moro (2005), no texto "Os ingredientes da Parentalidade", quanto à questão do mandato transgeracional, citando Lebovici (1995 apud MORO, 2005), são as falhas que persistiram nos conflitos infantis dos pais e que de alguma forma se repetem nos filhos. Tais conflitos podem estar acessíveis ou não, ou seja, inconscientes. As funções paterna e materna estão sujeitas ao funcionamento psíquico individual dos pais, portanto o sofrimento e ou traumas, não simbolizados pela mãe, podem se manifestar quando da constituição familiar ou de descendentes, em forma de depressão pós-parto e psicoses, que levam à incapacidade da mãe de desempenhar os cuidados maternos.

\section{Conclusões}

Após a apresentação e fundamentação das principais categorias conceituais e correntes de pensamento psicanalítico francês e argentino da transmissão psíquica geracional, podemos conferir, por meio de artigos científicos publicados, como esse tema é tratado por psicanalistas brasileiros. Podemos inferir, de início, que a influência psicanalítica franco-argentina é significativa e referência na produção científica da transgeracionalidade psíquica. Os artigos, na sua totalidade, trataram de casos clínicos relacionados à transmissão geracional. Assinala-se ainda que Freud influenciou, decerto, 
com suas teorias e metapsicologia, com os conceitos como inconsciente, recalcamento, pulsões, narcisismo, identificações e outros, que contribuem para a constituição teórica dos processos de base da transmissão psíquica.

Entretanto, ficou evidenciado também, além da utilização dos clássicos da psicanálise, como Freud, Abraham e Töroke dos psicanalistas franceses e argentinos, a forte influência da psicanálise lacaniana na fundamentação e abordagem do tema.

Lacan (1988, p. 123-124) vai dizer que o inconsciente é parte do discurso concreto enquanto transindividual e que falta para o sujeito recuperar a continuidade de seu discurso consciente. E mais, o inconsciente é o capítulo que falta da história do sujeito, que está em branco, ou ainda, que é uma mentira, vai dizer que é o capítulo censurado. "Mas o esquecido se lembra em seus atos, e a anulação se opõe ao que se diz em outra parte, como obrigação perpétua no símbolo, a miragem mesma onde o sujeito se encontrou preso." (LACAN, 1988, p. 126). A função da fala é evocar e o que nós procuramos nela é a resposta do outro. "O que me constitui como sujeito, é minha questão." (LACAN, 1988, p. 163). O simbólico é a linguagem, e esta é transmitida por transferência dos pais para o bebê, o sujeito é feito e efeito de significantes, portanto o que os cuidadores, os pais, os que cumprem essas funções lhe transmitirem ou transferirem marcará e constituirá o corpo pulsional, o sujeito do inconsciente.

Assinala-se, portanto, dos autores que constituem escolas, sobretudo os franceses, estes têm, na sua essência o trauma e suas formas de manifestação via transmissão psíquica, as fundamentações são metapsicológicas. Os autores que trabalharam na vertente psicanalítica lacaniana privilegiaram, na transmissão psíquica geracional, o simbólico, a cadeia significante, o inconsciente e, especialmente, a relação mãe-bebê, ou os pais, cuidadores e o bebê, no espaço intersubjetivo. Entretanto, o não dito, o não simbolizado, também se constitui em lugar comum da transmissão geracional nas relações familiares, seja no espaço transubjetivo, seja no intersubjetivo, e a sua repetição perpassa todas as correntes, contribuindo com os diferentes constructos. O sujeito pode transmitir aquilo que recebeu de seus ascendentes, mas para fazer a diferença na transmissão, "deverá" conquistar uma nova posição discursiva.

\section{Notas}

${ }^{1}$ O grande Outro para a psicanálise lacaniana representa, para além do outro parceiro do imaginário, um lugar simbólico, de produção de discursos e de significantes que é anterior e exterior ao sujeito e que o determina (CHEMAMA; VANDERMERSCH, 2007). Esse grande Outro para o bebê, por exemplo, será a mãe ou quem cumprir a função materna. 


\section{REFERÊNCIAS}

ABRAHAM, N.; TÖROK, M. A casca e o núcleo. São Paulo: Escuta, 1995.

AGUIAR, F. Psicanálise e Universidade: das relações entre a Psicologia Clínica e a Psicanálise na França. Estud. psicol. (Natal), Natal, v. 5, n. 1, p. 215-241, jun. 2000. Disponível em: <http://www.scielo.br/scielo.php?script=sci arttext\&pid=S1413-294X2000000100010\&lng=en\&nrm=iso>. Acesso em: $0 \overline{4}$ jan. 2011. doi: 10.1590/S1413-294X2000000100010.

ALMEIDA, M. E. S. A força do legado transgeracional numa Família. Psicologia: Teoria e Prática, São Paulo, v. 10, n. 2, p. 215-230, 2008.

ANTUNES, S. P. Os caminhos do trauma em Nicolas Abraham e Maria Törok. São Paulo: Escuta, 2003.

ARAUJO, M. L. O discurso dos pais na clínica psicanalítica com crianças: significantes transgeracionais em questão.. In: COLOQUIO DO LEPSI IP/FE-USP, 3., 2001, São Paulo. Anais eletrnicos... Disponvel em: <http://www.proceedings.scielo.br/scielo.php? script=sci arttext\&pid=MSC0000000032001000300025\&lng=pt\&nrm=abn>. Acesso em: 24 dez. 2010.

BENGHOZI, P. Traumatismos precoces da criança e transmissão genealógica em situação de crises e catástrofes humanitárias: desemalhar e reemalhar continentes genealógicos familiares e comunitários. In: CORREA, O. (Org.). Os avatares da transmissão psíquica geracional. São Paulo: Escuta, 2001. p.89-100.

CHEMAMA, R., VANDERMERSCH, B. Dicionário de Psicanálise. São Leopoldo, RS: Unisinos, 2007.

CARRETEIRO, T. C.; FREIRE, L. de L. De mãe para filha: a transmissão familiar em questão. Psicologia Clínica, Rio de Janeiro, v. 15, n. 2, p. 179-191, 2003.

CORREA, O. B. R. (Org.). Colóquio em homenagem a Nicolas Abraham e Maria Törok. In: . Os avatares da transmissão psíquica geracional. São Paulo: Escuta, 2000a. p. 9-16.

CORREA, O. B. R. (Org.). Eclosão dos vínculos genealógicos e transmissão psíquica. In: . Os avatares da transmissão psíquica geracional. São Paulo: Escuta, 2000b. p. 61-71.

CORREA, O. B. R. (Org.). Transmissão psíquica entre as gerações. Psicologia USP, São Paulo, v. 14, n. 3, p. 35-45, 2003. 
FAIMBERG, H. A telescopagem das gerações a propósito da genealogia de certas identificações. In: KAËS et al. Transmissão da vida psíquica entre gerações. São Paulo: Casa do Psicólogo, 2001a. p.71-93.

FAIMBERG, H. Escuta da Telescopagem das gerações: pertinência psicanalítica do conceito. In: . Transmissão da vida psíquica entre gerações. São Paulo: Casa do Psicólogo, 2001b. p. 129-145.

FREUD, S. Totem e Tabu (1913). In: . Obras Psicológicas Completas de Sigmund Freud. Rio de Janeiro: Imago, 1974. v. XIII, p. 13-194. Edição Standard Brasileira.

FREUD, S. Sobre o Narcisismo: uma introdução (1914). In: . Obras Psicológicas Completas de Sigmund Freud. Rio de Janeiro: Imago, 1974. v. XIV, p. 85-119. Edição Standard Brasileira.

FREUD, S. Os Instintos e suas vicissitudes (1915). In: . Obras Psicológicas Completas de Sigmund Freud. Rio de Janeiro: Imago, 1974. v. XIV, p. 129-162. Edição Standard Brasileira.

FREUD, S. Psicologia de Grupo e a Análise do ego (1921). In: . Obras Psicológicas Completas de Sigmund Freud. Rio de Janeiro: Imago, 1974. v. XVIII, p. 89-179. Edição Standard Brasileira.

FREUD, S. A Negativa (1925). In: Obras Psicológicas Completas de Sigmund Freud. Rio de Janeiro: Imago, 1974. v. XIX, p. 293-300. Edição Standard Brasileira.

FREUD, S. O Mal-estar na Civilização (1930). In: . Obras Psicológicas Completas de Sigmund Freud. Rio de Janeiro: Imago, 1974. v. XXI, p. 75-171. Edição Standard Brasileira.

GOLDFARB, D. C.; LOPES, R. G. da C. Avosidade: a família e a transmissão psíquica entre gerações. In: FREITAS, E. V.; PY, L.; NERI, A. L. (Org.). Tratado de Geriatria e Gerontologia. 2. ed. Rio de Janeiro: Guanabara-Koogan, 2006. cap. 147, p. 1375-1381.

GOMES, I. C.; ZANETTI, S. A. S. Transmissão psíquica transgeracional e construção de subjetividade: relato de uma psicoterapia psicanalítica vincular. Psicologia USP, SãoPaulo, v.20,n. 1,p.93-108,2009. Disponívelem:<http://www. scielo.br/scielo.php? script=sci_arttext\&pid=S0103-65642009000100006>. Acesso em: 12 nov. 2010.

GRANJON, E. A elaboração do tempo genealógico no espaço do tratamento da terapia familiar psicanalítica. In: CORREA, O. (Org.). Os avatares da transmissão 
psíquica geracional. São Paulo: Escuta, 2000. p. 17-43.

KAËS, R. Um pacto de resistência intergeracional ao luto: transmissão psíquica dos efeitos da morte de uma criança sobre os irmãos e irmãs e sobre sua descendência. In: CORREA, O. (Org.). Os avatares da transmissão psíquica geracional. São Paulo: Escuta, 2000. p. 45-59.

LACAN, J. Função e campo da fala e da linguagem em psicanálise. In: Escritos. São Paulo: Perspectiva, 1988. p. 101-187.

LACAN, J. Os complexos familiares (1938). Rio de Janeiro: J. Zahar, 1987.

LACAN, J. Nota sobre a criança. In: Outros Escritos. Rio de Janeiro: J. Zahar, 2003. p. 369-70.

MORO, M. R. Os ingredientes da parentalidade. Revista Lationoamericana Psicopatologia Fundamental, São Paulo, v. VIII, n. 2, p. 258-53, 2005.

PUGET, J. Disso não se fala... Transmissão e memória. In: CORREA, O. (Org.). Os avatares da transmissão psíquica geracional. São Paulo: Escuta, 2000. p. 73-87.

PIVA, A. A Fragilidade do Símbolo e a Transmissão Transgeracional. Contemporânea - Psicanálise e Transdisciplinaridade, Porto Alegre, n. 07, p. 74-85, jan./fev./mar. 2009.

Recebido em: 07 de fevereiro de 2011 Aceito em:07 de agosto de 2013 
